Supporting Information

\title{
Porosity Modulated High-Performance Piezoelectric Nanogenerator Based on Organic/Inorganic Nanomaterial for Self-Powered Structural Health Monitoring
}

Md Masud Rana ${ }^{1}$, Asif Abdullah Khan ${ }^{1}$, Guangguang Huang ${ }^{1 *}$, Nanqin Mei ${ }^{2}$, Resul Saritas ${ }^{3}$, Boyu Wen $^{1}$, Steven Zhang ${ }^{1}$, Peter Voss ${ }^{4}$, Eihab Abdel-Rahman ${ }^{3}$, Zoya Leonenko ${ }^{2}$, Shariful Islam ${ }^{4}$, Dayan $\mathrm{Ban}^{1,5^{*}}$

${ }^{1}$ Waterloo Institute for Nanotechnology, University of Waterloo (200 University Ave. West, Waterloo, ON, Canada)

${ }^{1}$ Department of Electrical and Computer Engineering, University of Waterloo (200 University Ave. West, Waterloo, ON Canada)

${ }^{2}$ Department of Physics \& Astronomy, University of Waterloo (200 University Ave. West, Waterloo, ON Canada)

${ }^{3}$ Department of Systems Design Engineering, University of Waterloo (200 University Ave. West, Waterloo, ON Canada)

${ }^{4}$ Shimco North America Inc. (75 Heroux Devtek Dr, Cambridge, ON, Canada)

${ }^{5}$ School of Physics and Electronics, Henan University, No. 1 Jinming street, Kaifeng, Henan, P. R. China

Email: g43huang@uwaterloo.ca (G. Huang), dban@uwaterloo.ca (D. Ban) 
(a)
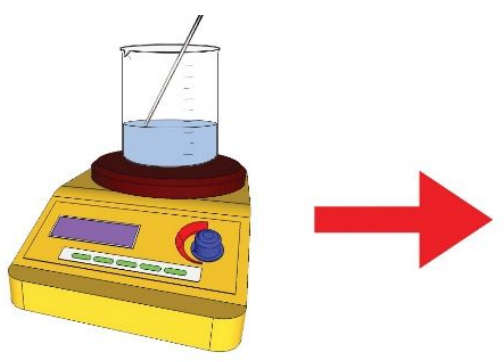

(f)
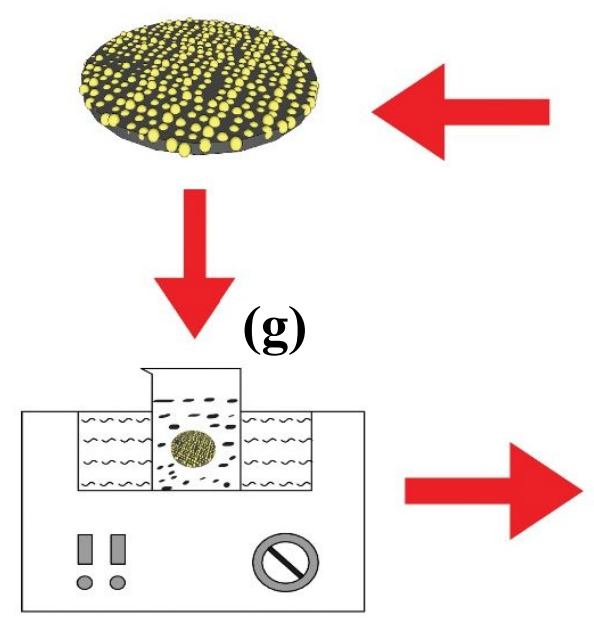

(b)

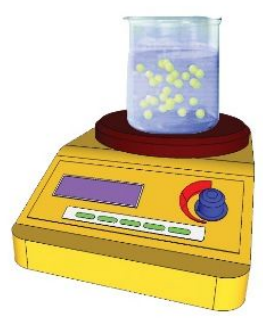

(e)

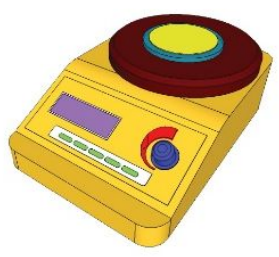

(h) (c)
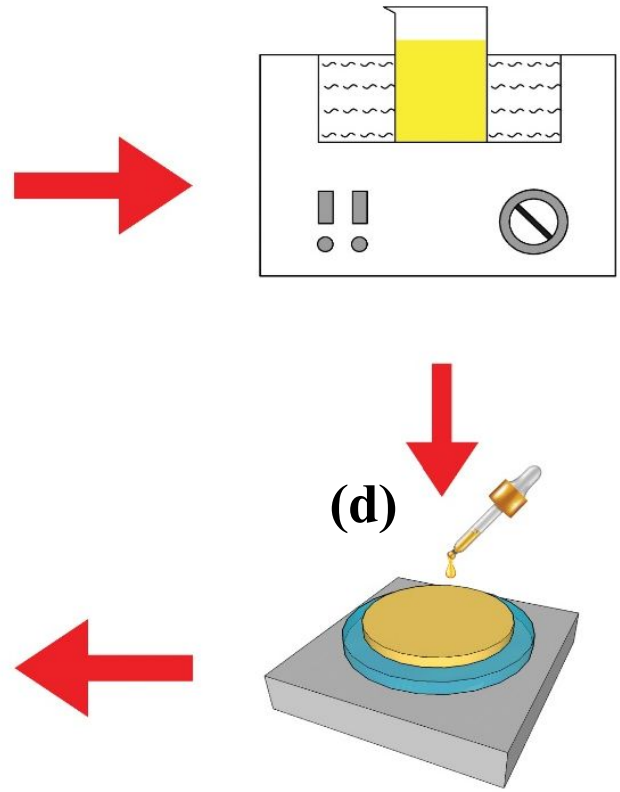

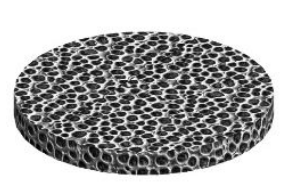

(i)
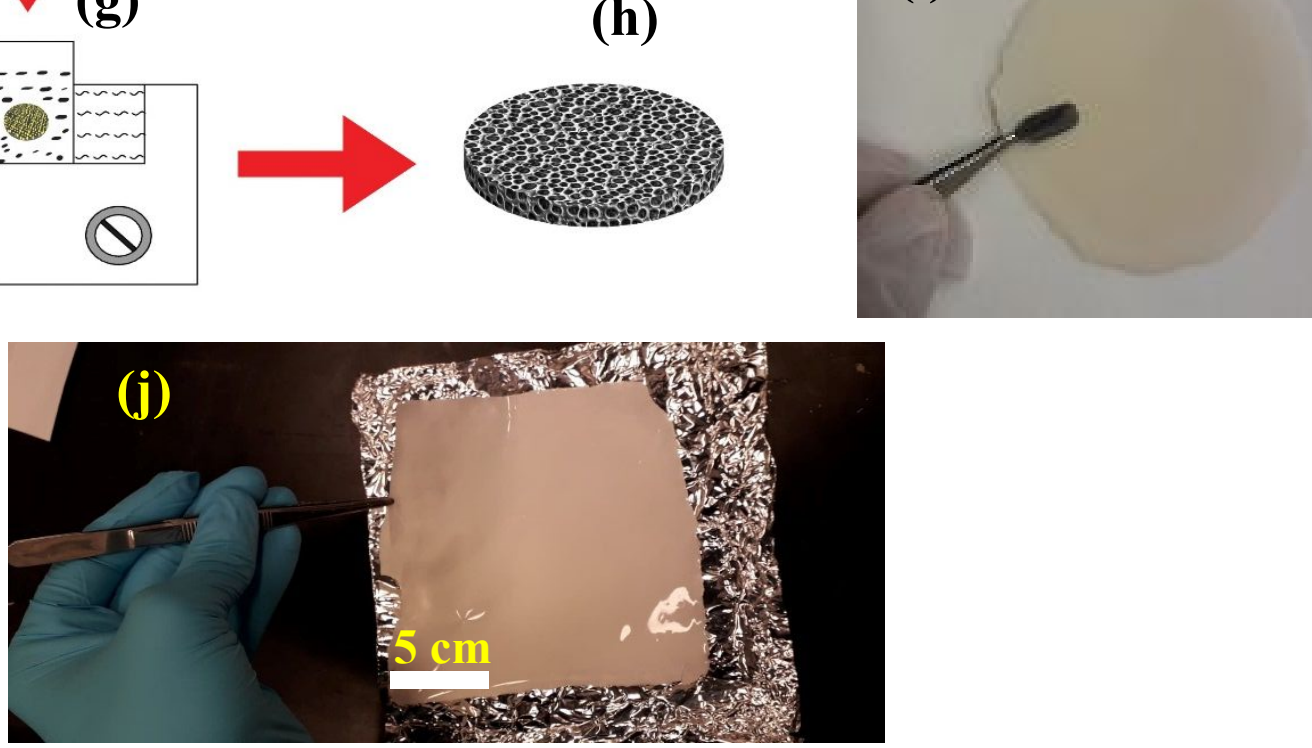

Figure S1. Step-by-step fabrication process of the Porous PVDF thin film (a) PVDF powder (Sigma Aldrich) is dissolved in N, N-dimethylformamide (N, N-DMF) solvent (10 wt. \%). (b) ZnO NPs (35-45 $\mathrm{nm}$, US Research Nanomaterials, Inc.) are mixed within the PVDF matrix solution. and stirred for 4 hours. (c) Ultra-sonication for 30 min to maximize the uniform distribution of $\mathrm{ZnO}-\mathrm{NPs}$ within the PVDF polymer matrix. (d) The suspension drops cast onto a $\mathrm{Si}$ wafer (e) Degassing is done for 30 minutes at $65^{\circ} \mathrm{C}$ and then annealing at a slightly elevated temperature $\left(75^{\circ} \mathrm{C}\right)$ for another 45 minutes. (f)The films peeled off from the Si substrate. (g) Etching with $37 \mathrm{wt}$. \% $\mathrm{HCl}$ solution for 4 hours to completely etch off $\mathrm{ZnO}$ NPs from the PVDF matrix. (h) Final porous PVDF thin films are ready for device fabrication. (i) Fabricated film (j) large scale fabricated film $(15 \mathrm{~cm} \times 15 \mathrm{~cm})$ 

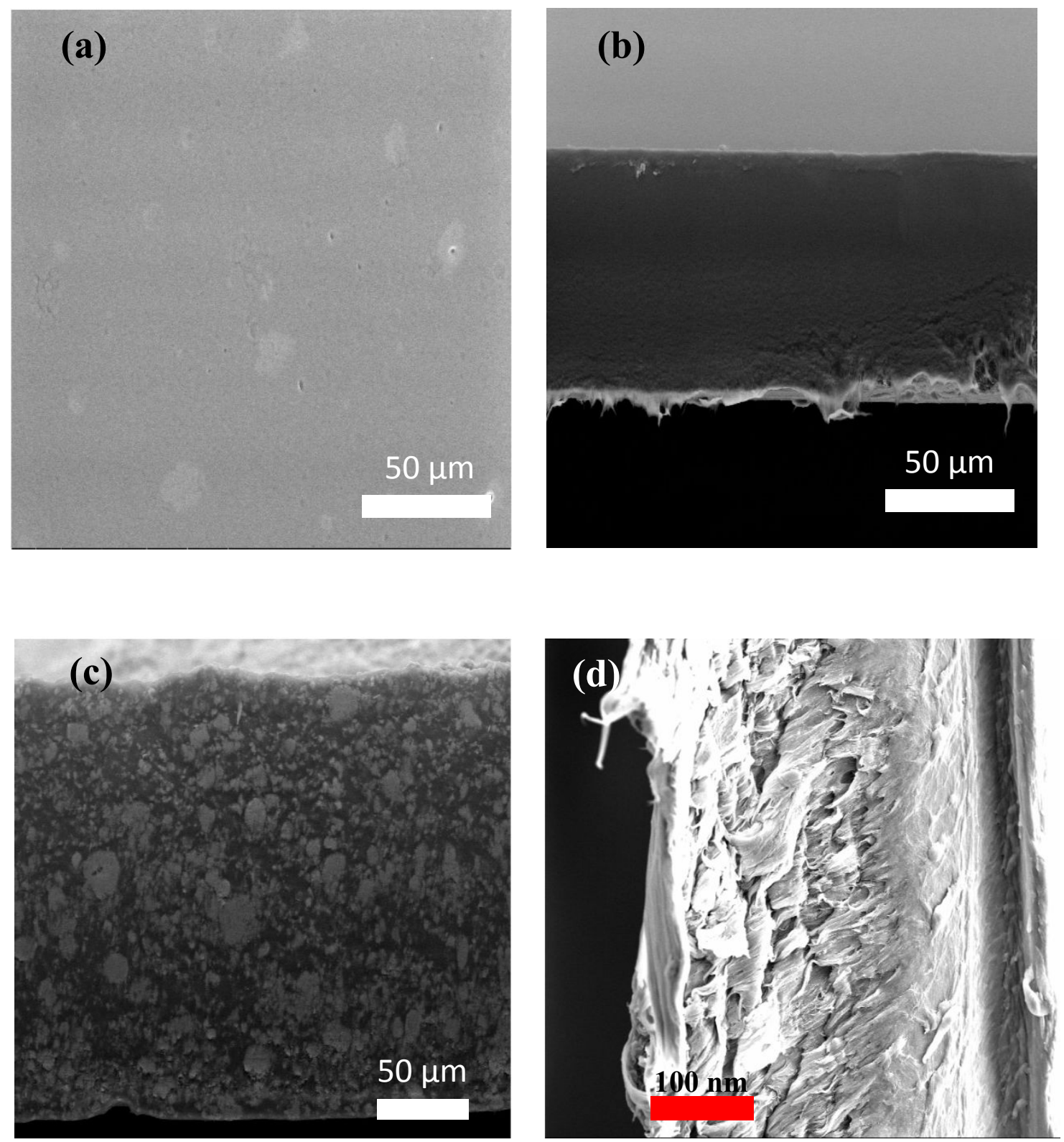

Figure S2. The characterization of the pure and porous PVDF film. scanning electron microscope (SEM) images of the pure PVDF film (a) Plane view SEM (b) Cross-sectional SEM, annealed at $75^{\circ} \mathrm{C}$, the SEM image indicates that the surface of the pure PVDF is uniform for both cases (c) distributed ZnO NPs on the surface of the PVDF matrix. (c) the cross-sectional SEM image of the PVDF mixed with ZnO NPs, The SEM image indicates that nanoparticles are not uniformly distributed rather accumulated in different positions of the PVDF film. This creates pores of different sizes after an etching process. (d) Cross-sectional SEM image of the porous PVDF film after the etching of the ZnO NPs 

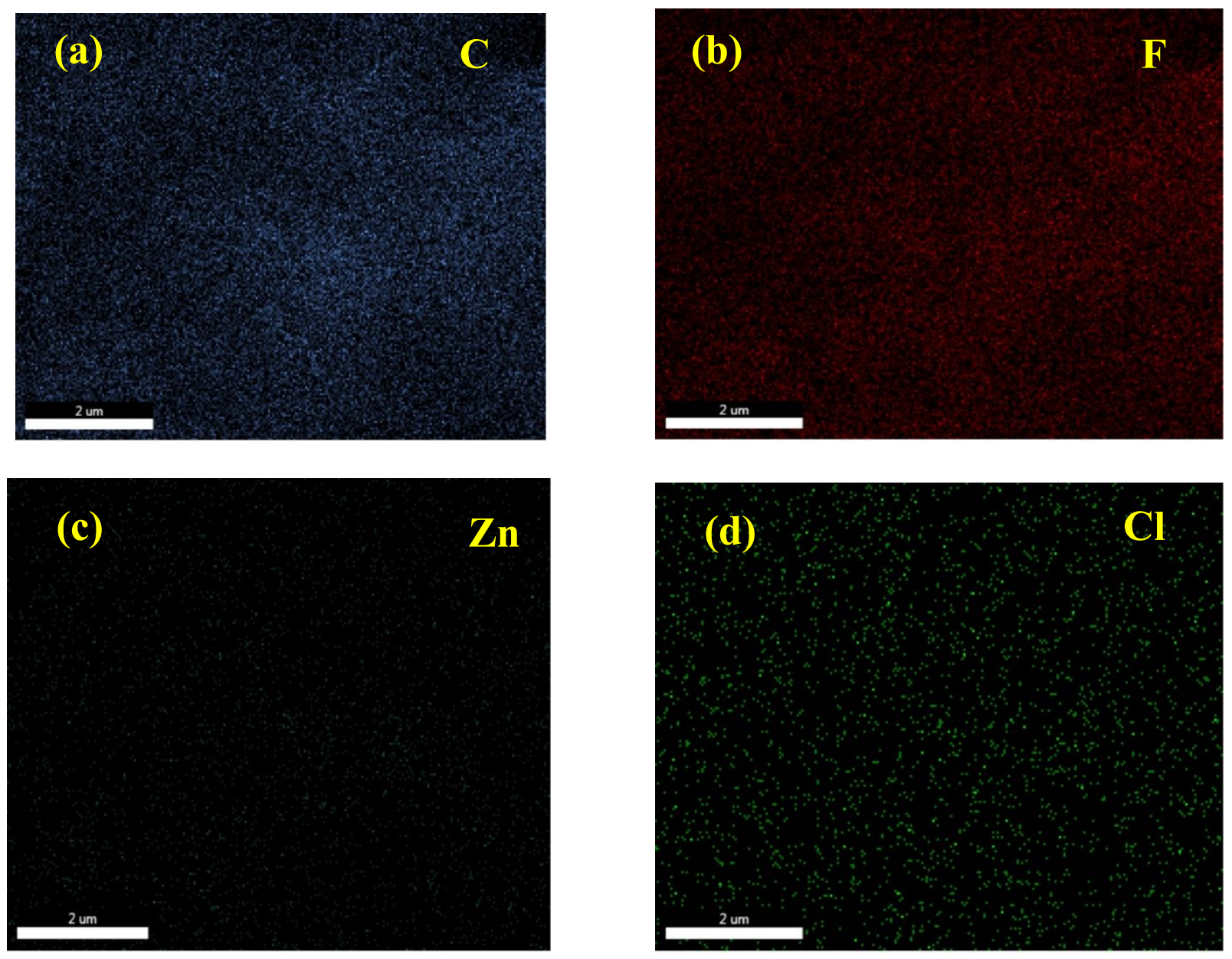

(e)

\begin{tabular}{|c|c|c|c|}
\hline Element & Weight $\%$ & Atomic $\%$ & Net Int. \\
\hline C K & 68.46 & 77.69 & 731.4 \\
\hline F K & 30.73 & 22.05 & 458.3 \\
\hline ZnL & 0.29 & 0.06 & 2.4 \\
\hline ClK & 0.51 & 0.20 & 5.8 \\
\hline
\end{tabular}

Figure S3. Element mapping of (a) Carbon (C); (b) fluorine (F); (c) Zinc (Zn); (d) Chlorine (Cl); in porous PVDF thin film for a specific region of interest. (e) compare the quant results of elements in the porous film. 

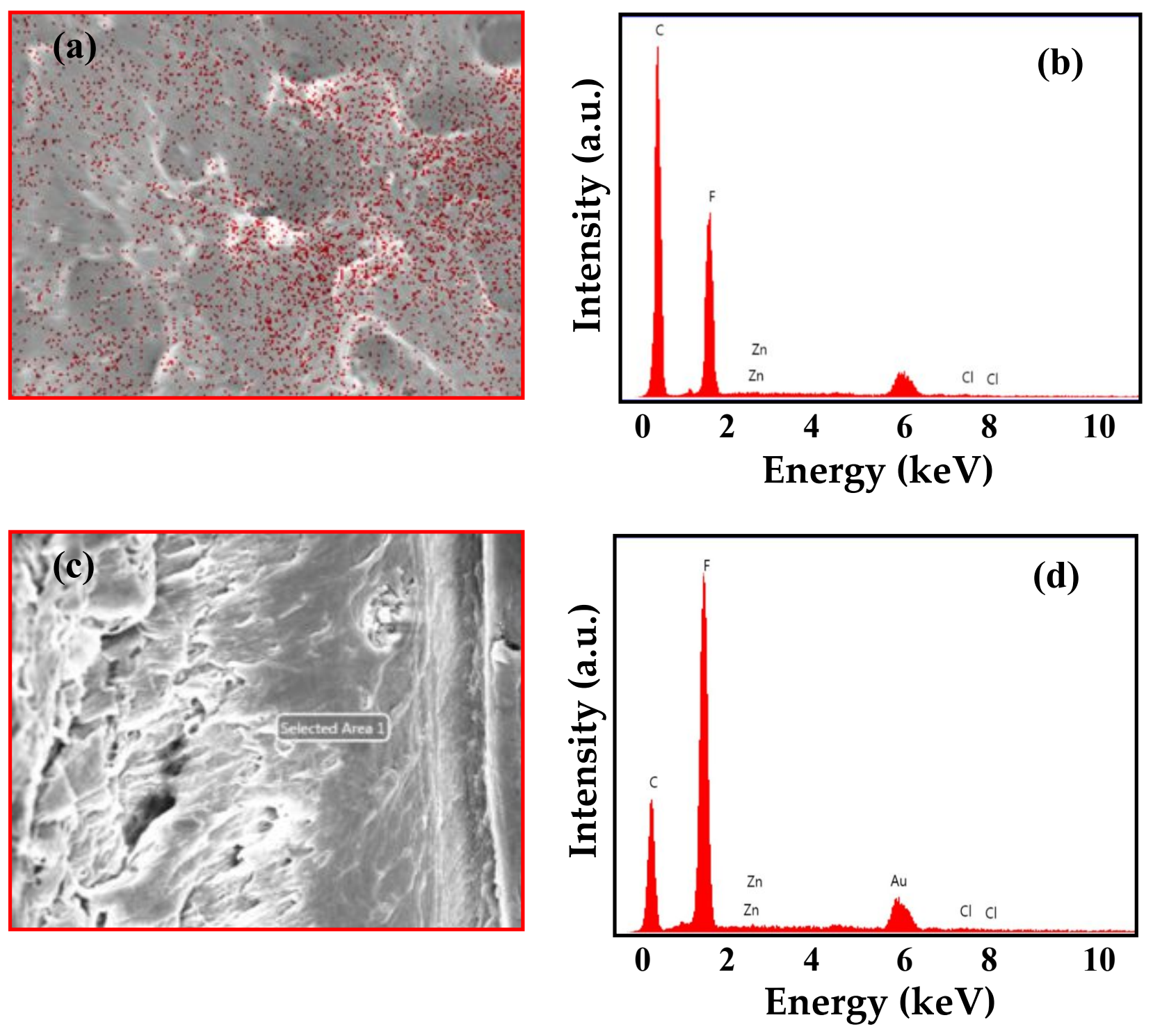

Figure S4. (a) The selected area of top surface SEM of nanoporous PVDF film; (b) EDS spectrum of the nanoporous PVDF film of image (a); (c) Selected area of cross-sectional SEM of nanoporous PVDF film; (d) EDS spectrum of the nanoporous PVDF film of image (c); 
(a)

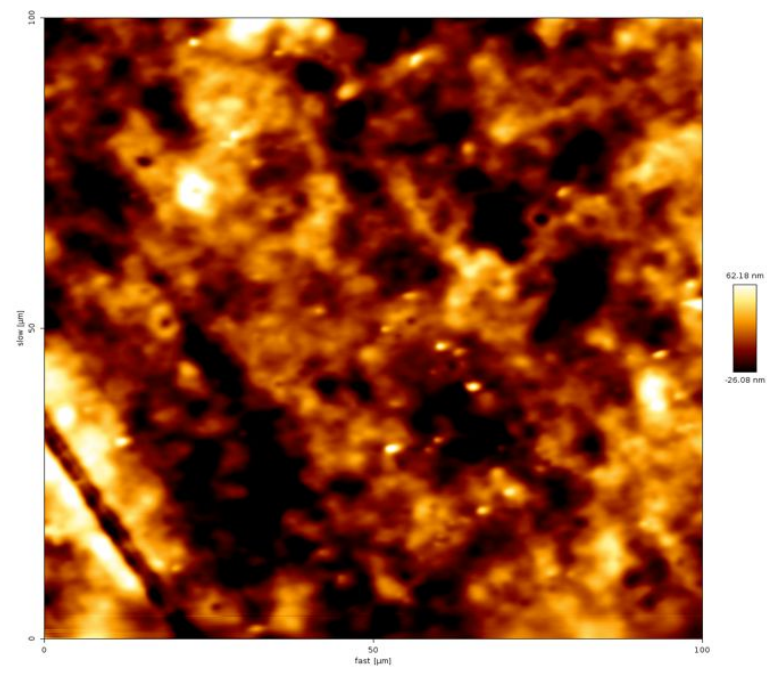

(b)

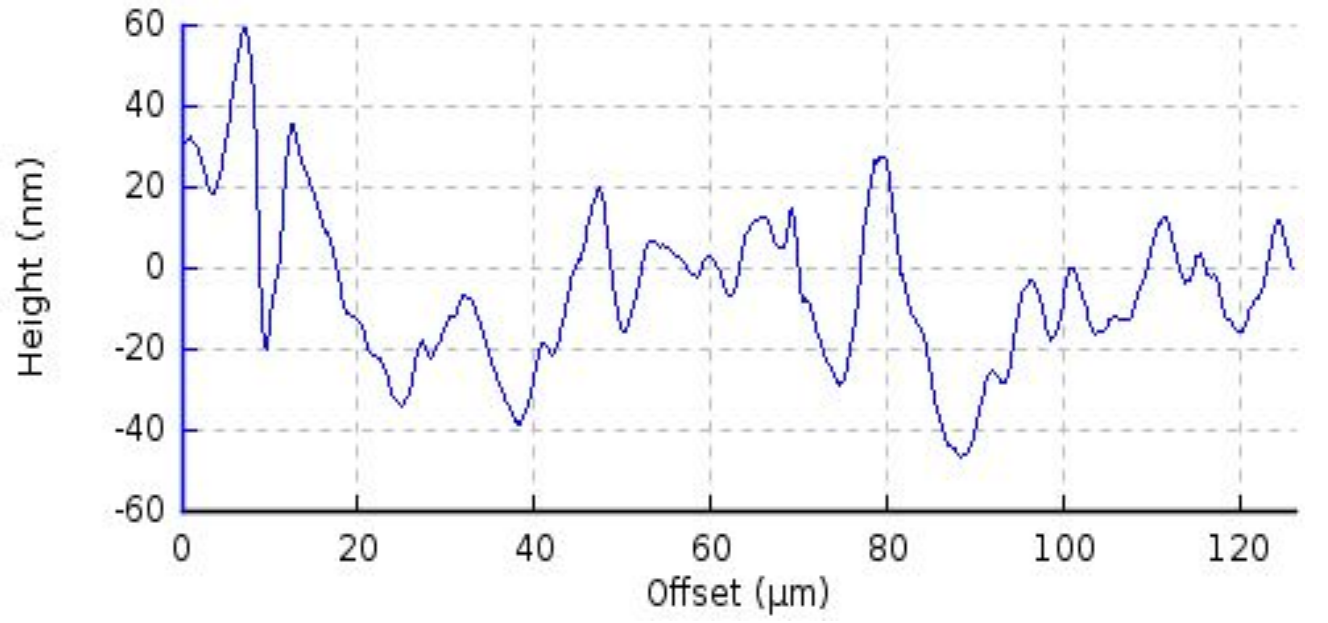

Figure S5. The characterization of the porous PVDF film (a) the atomic force microscopy (AFM) image of porous PVDF surface (b) measured surface roughness of porous PVDF ( 100 $\mathrm{nm})$ 
Before poling After poling

(a)
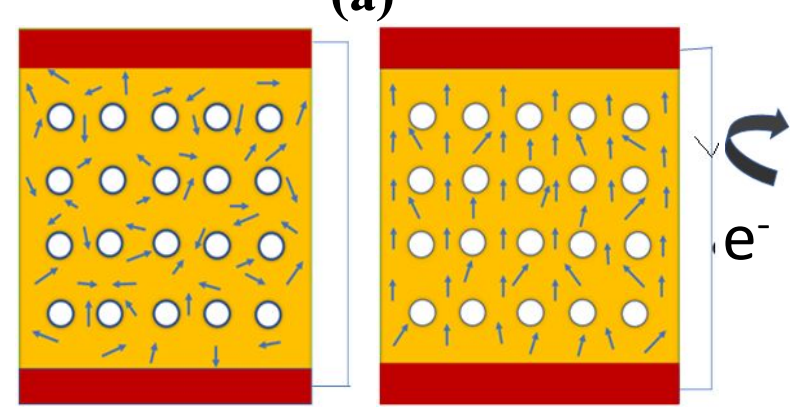

(b)
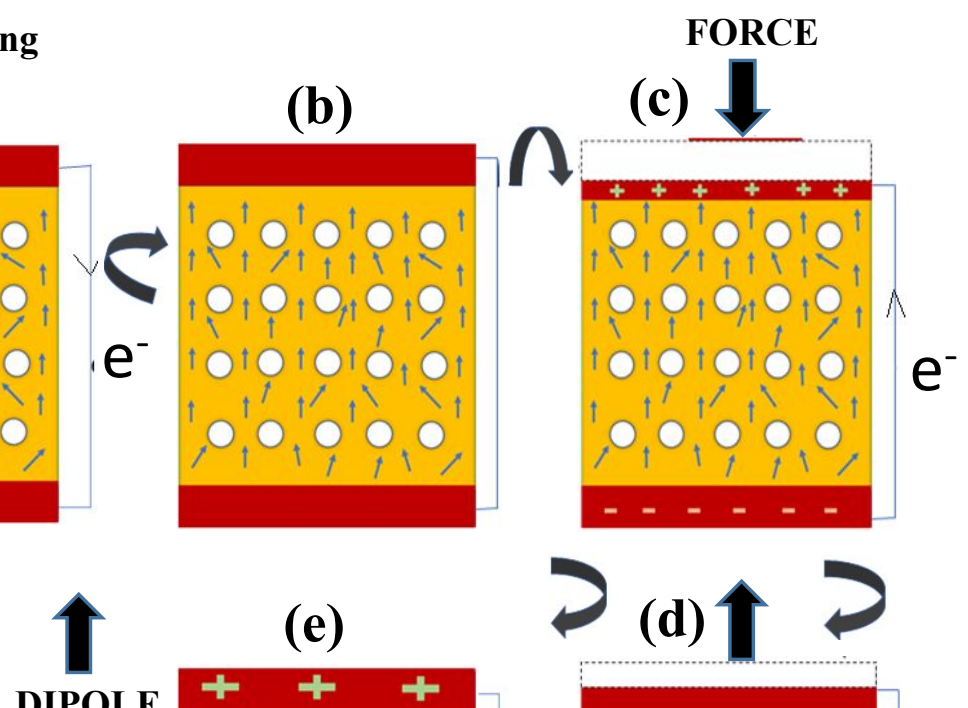

DIPOLE

(e)
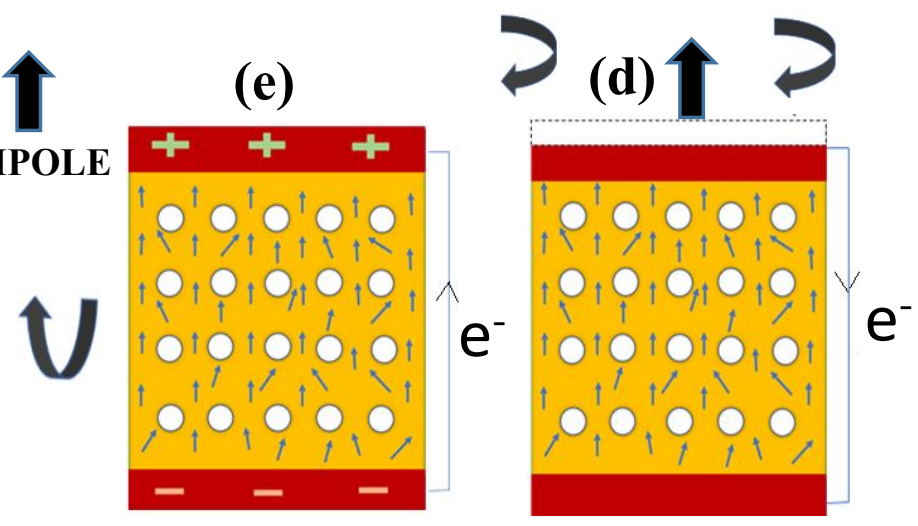

Figure S6. Schematics of the energy generation mechanism from the PENG by considering distributed stress on the film. 
(a)

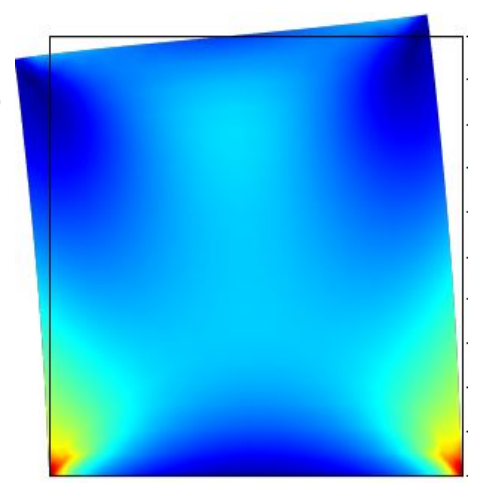

(c)

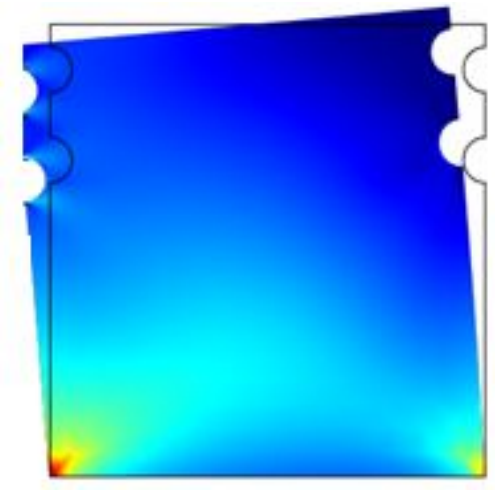

(b)
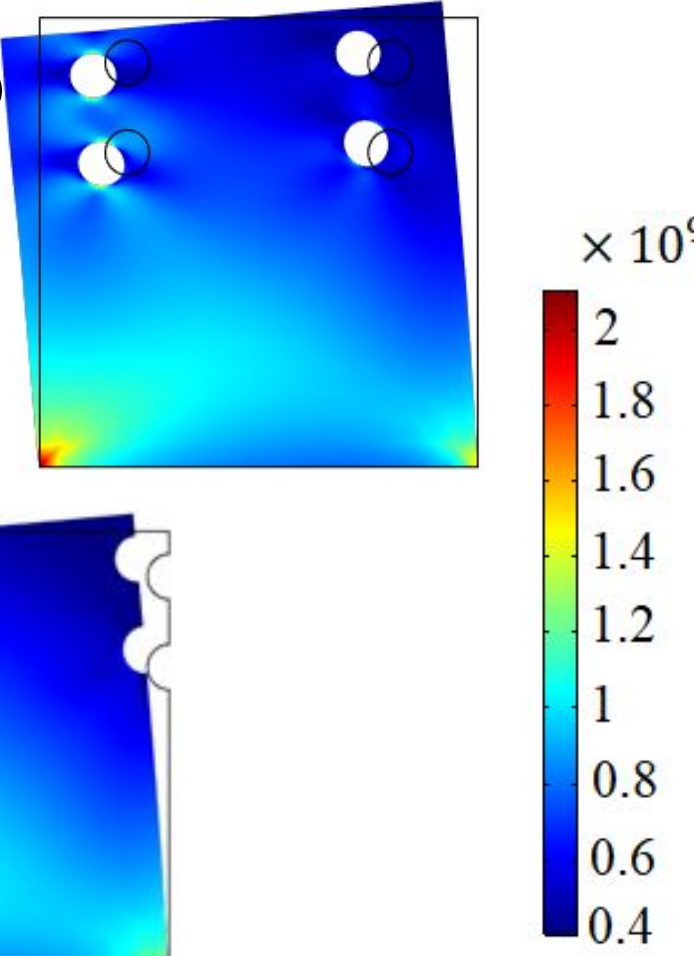

Figure S7. Strain distribution in the porous PVDF with varying porosity under a lateral bending force of $2 \mathrm{GPa}$ (a) pure (0\%) PVDF (b) porous PVDF with inner pores only, and (c) porous PVDF with only surface pores. The scale bar is the same for all profiles from (a-c). 
(a)

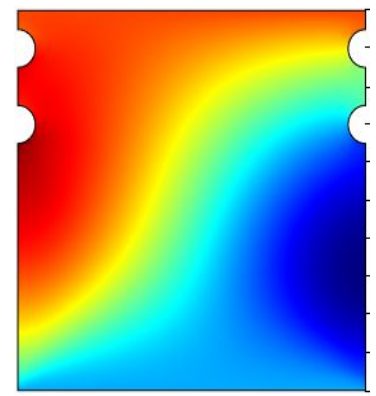

(b)

(c)
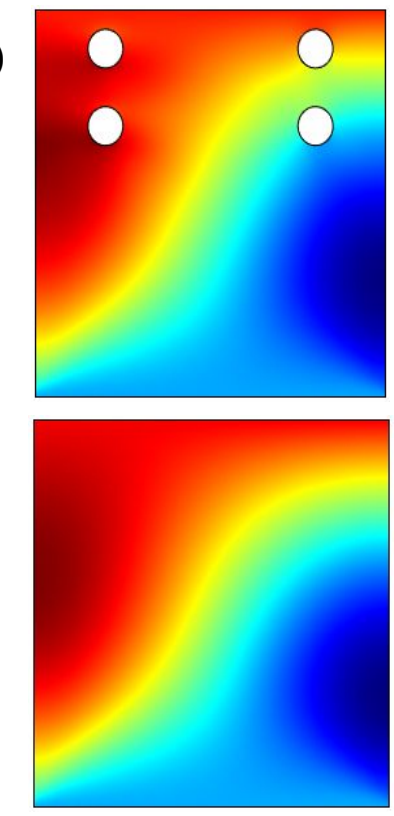
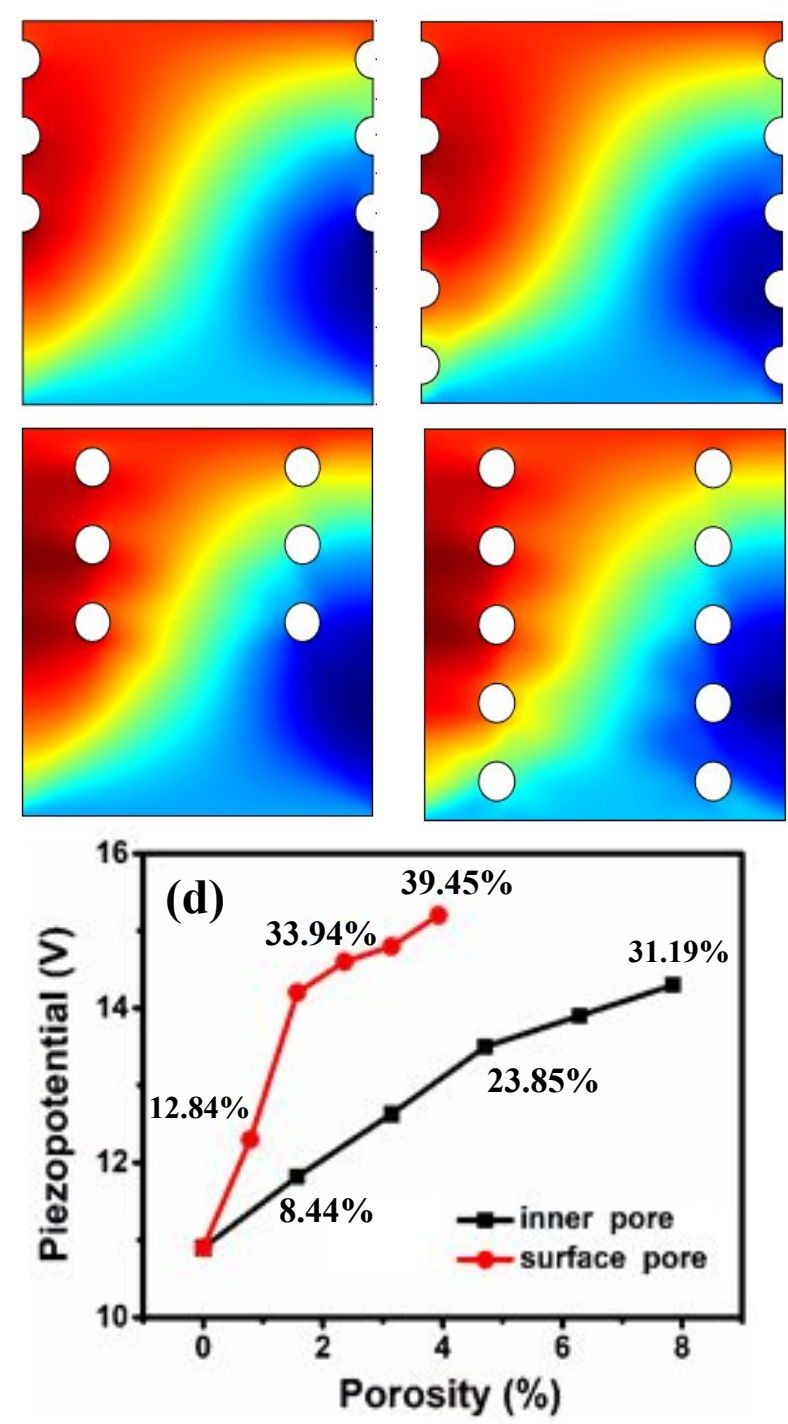

Figure S8. Piezopotential distribution in the porous PVDF model with varying porosity percentages under lateral bending force (a) with surface pores only, (b) with only inner pores, and (c) a non-porous PVDF. Same scale bar for (a-c) (d) comparison of piezopotential as a function of porosity.

Supporting note S1: Here a PVDF piezoelectric polymer is used to study the simple cases of the porous structure, where a square $(100 \mathrm{~nm} \times 100 \mathrm{~nm}) 2 \mathrm{D}$ model is developed. To make the structure porous, we then intentionally incorporate inner and surface circular nano-pores, with a pore size of $5 \mathrm{~nm}$ radius. Here we summarize a comparison between three basic models that included a non-porous (pure) PVDF, a porous PVDF with surface pores, and a porous PVDF with inner pores only, with different porosity concentration, having spatially uniform pore distributions. To study the piezoelectricity of the porous structure a lateral bending force of $2 \mathrm{GPa}$ is uniformly applied on the side surface. Figure S8a-c shows the simulation results, revealing the piezopotential is substantially modified due to the presence of pores. More specifically, the piezopotential increases proportionally with the degree of porosity, which is represented by the brightness of color grading. The potential is raised by $39.45 \%(10.9 \mathrm{~V}$ to $15.2 \mathrm{~V})$ when the porosity increases from 
zero to $3.9 \%$ if pores are on the surface and the potential is raised by $31.19 \%(10.9 \mathrm{~V}$ to $14.3 \mathrm{~V})$ when the porosity increases from zero to $7.85 \%$ if pores are inside (Figure S8d).

Table S1: Comparison of percentage increases of piezopotential with porosity

\begin{tabular}{|c|c|c|c|c|c|}
\hline \multicolumn{6}{|c|}{ Lateral Bending force } \\
\hline \multicolumn{3}{|c|}{ Surface Pore Condition } & \multicolumn{3}{|c|}{ Inner Pore condition } \\
\hline $\begin{array}{c}\% \text { of } \\
\text { Porosity }\end{array}$ & $\begin{array}{c}\text { Piezo- } \\
\text { potential (V) }\end{array}$ & $\begin{array}{c}\% \text { of Voltage } \\
\text { increase }\end{array}$ & $\begin{array}{c}\% \text { of } \\
\text { Porosity }\end{array}$ & $\begin{array}{l}\text { Piezo- } \\
\text { potential } \\
\text { (V) }\end{array}$ & $\begin{array}{l}\% \text { of Voltage } \\
\text { increase }\end{array}$ \\
\hline 0 & 10.9 & - & 0 & 10.9 & - \\
\hline 0.79 & 12.3 & 12.84 & 1.57 & 11.82 & 8.44 \\
\hline 1.57 & 14.2 & 30.27 & 3.14 & 12.63 & 15.87 \\
\hline 2.36 & 14.6 & 33.94 & 4.71 & 13.50 & 23.85 \\
\hline 3.14 & 14.8 & 35.79 & 6.28 & 13.90 & 27.52 \\
\hline 3.93 & 15.2 & 39.45 & 7.85 & 14.30 & 31.19 \\
\hline \multicolumn{6}{|c|}{ Compressive force } \\
\hline \multicolumn{3}{|c|}{ Surface Pore Condition } & \multicolumn{3}{|c|}{ Inner Pore condition } \\
\hline $\begin{array}{c}\% \text { of } \\
\text { Porosity }\end{array}$ & $\begin{array}{c}\text { Piezo- } \\
\text { potential }(\mathrm{V})\end{array}$ & $\begin{array}{c}\% \text { of Voltage } \\
\text { increase }\end{array}$ & $\begin{array}{c}\% \text { of } \\
\text { Porosity }\end{array}$ & $\begin{array}{c}\text { Piezo- } \\
\text { potential }(\mathrm{V})\end{array}$ & $\begin{array}{c}\% \text { of Voltage } \\
\text { increase }\end{array}$ \\
\hline 0 & 46.6 & - & 0 & 46.6 & - \\
\hline 0.79 & 47.2 & 1.29 & 1.57 & 47.8 & 2.58 \\
\hline 1.57 & 47.7 & 2.36 & 3.14 & 49.1 & 5.36 \\
\hline 2.36 & 48.2 & 3.43 & 4.71 & 50.3 & 7.94 \\
\hline 3.14 & 48.7 & 4.51 & 6.28 & 51.6 & 10.73 \\
\hline 3.93 & 49.3 & 5.79 & 7.85 & 53 & 13.73 \\
\hline
\end{tabular}

$\%$ of porosity Calculation for Inner pore

Radius of pore $=5 \mathrm{~nm}$

Area of pore $=3.1416 * 25=78.54 \mathrm{~nm}^{2}$

Area of PVDF $=10000 \mathrm{~nm}^{2}$

$\%$ of porosity in the PVDF $=(78.54 / 10000) * 100 \%=.79 \%$ for a single pore

For surface pore, this will be half as the surface contain only the half portion of the circle. 

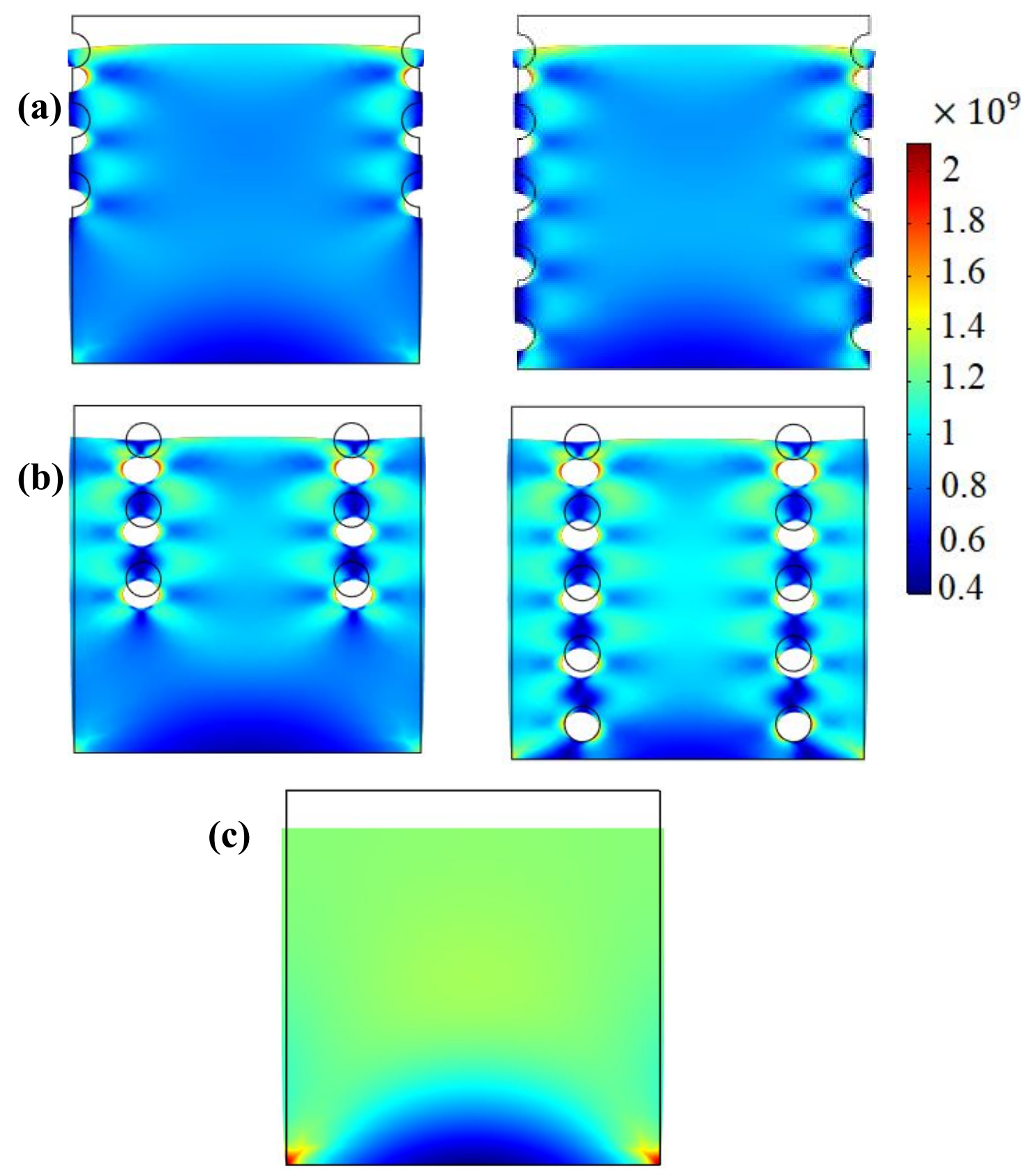

Figure S9. Strain distribution in the porous PVDF with varying porosity under a vertical compressive force of 2 GPa (a) porous PVDF with only surface pores, (b) porous PVDF with inner pores only, and (c) pure PVDF, The scale bar is the same for all profiles from (a-c). 


\section{Supporting note S2:}

As shown in Figure S9a for surface pores and Figure S9b for inner pores, when we applied the compressive force the stress of pores deformed asymmetrically. The strain concentration near both sides of the pores is much more significantly visualize which indicates tensile strain creation at both sides of the pores compared to its bulk counterpart (Figure S9c). As we discussed earlier that the piezopotential is the result of combined dipole moments that form due to the displacement of positive and negative charge centers upon application of external stress, these dipole moments add together and provide the positive and negative piezopotential. This localized strain of higher magnitude induces higher potential, which adds up and enhances the bulk piezopotential. 
(a)

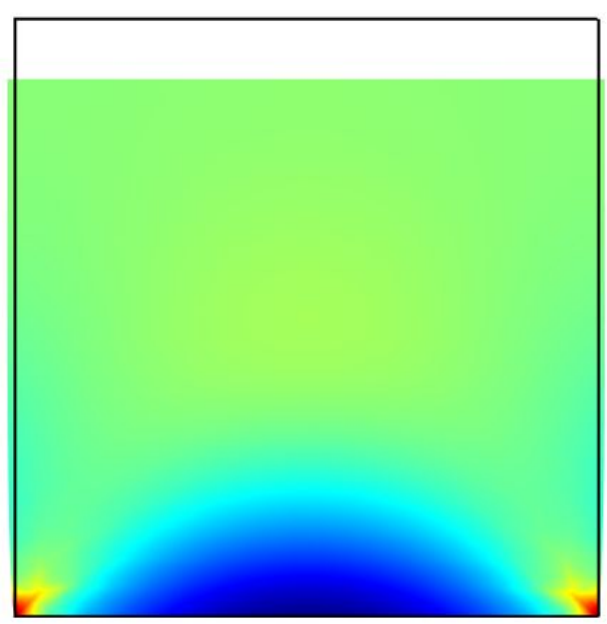

(b)

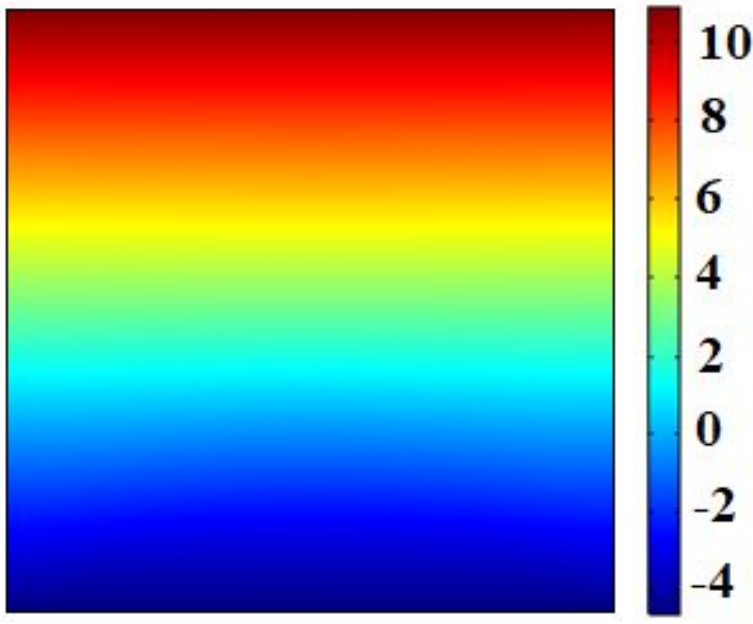

(c)

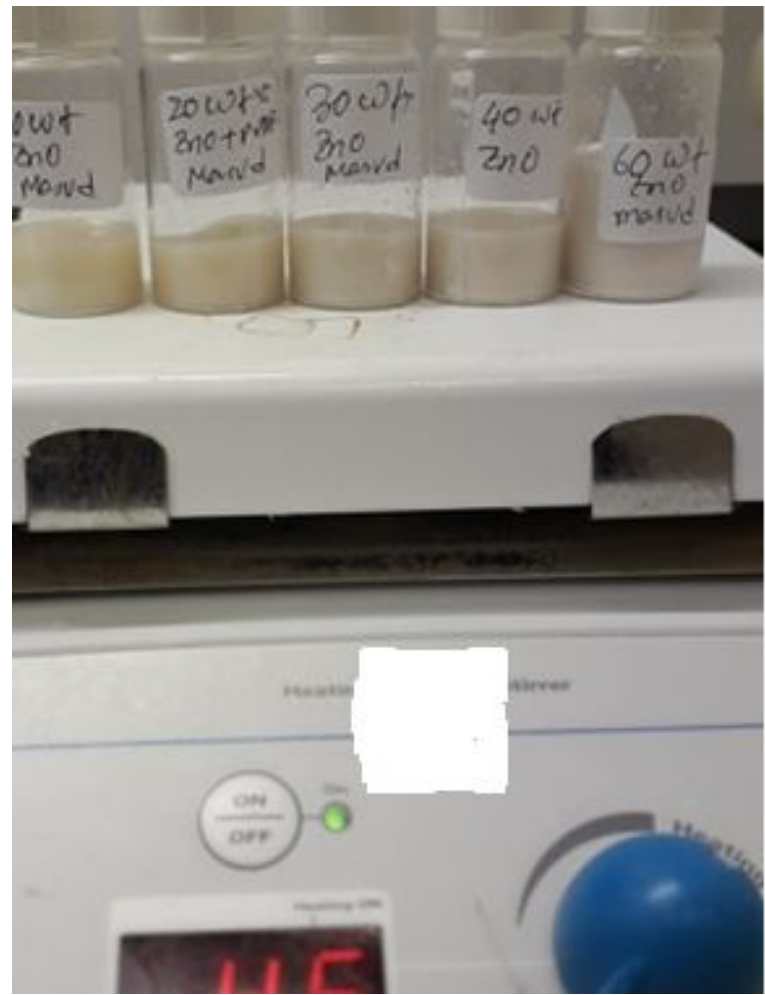

Figure S10. (a) Stress distribution for pure PVDF film (b) potential distribution for pure PVDF film where the peak output voltage is 10.9 volt, (c) prepared solution of PVDF-ZnO with a $\mathrm{ZnO}$ mass ratio of 0 to $60 \mathrm{wt} . \%$ ( 0 and $50 \mathrm{wt}$. \% are not shown here). 

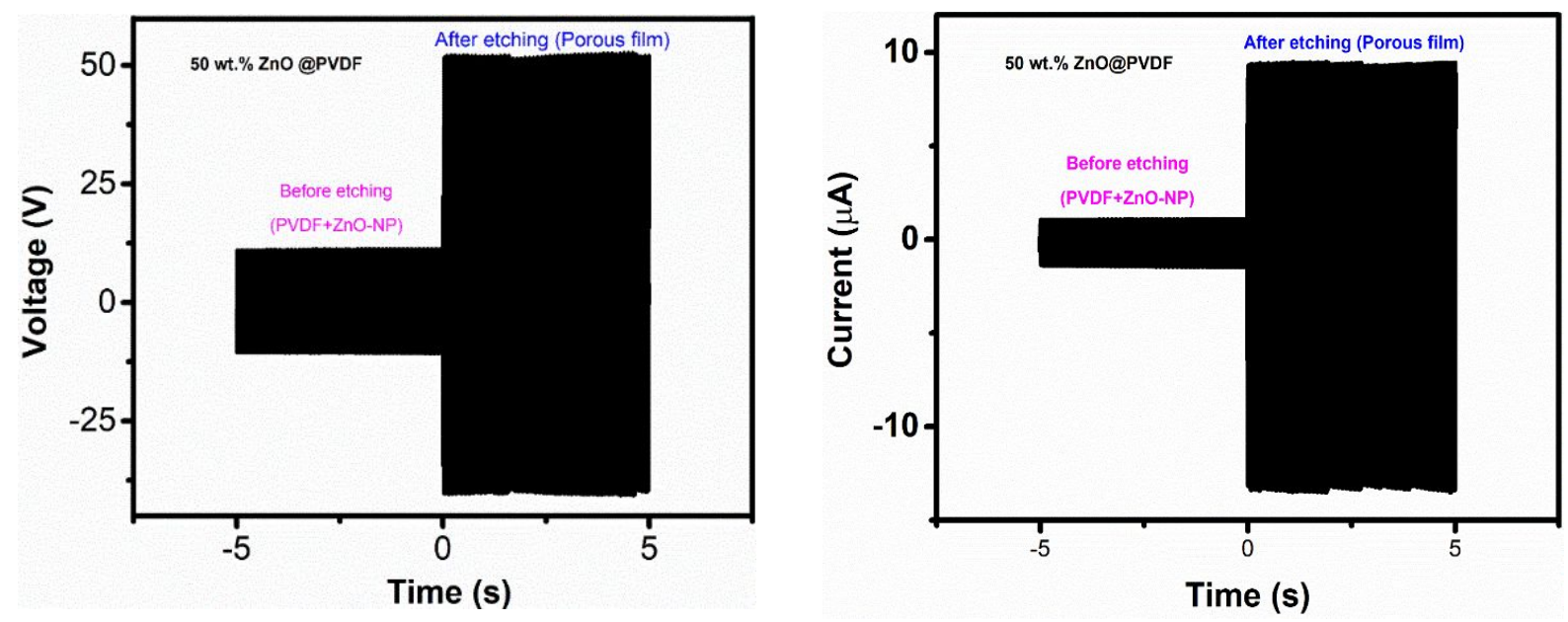

Figure S11. Comparison of the electrical output performance for 50 wt. \% of $\mathrm{ZnO}-\mathrm{NP}$ based PVDF porous and nonporous film . (a) Output voltage (b) output current. 
(a)

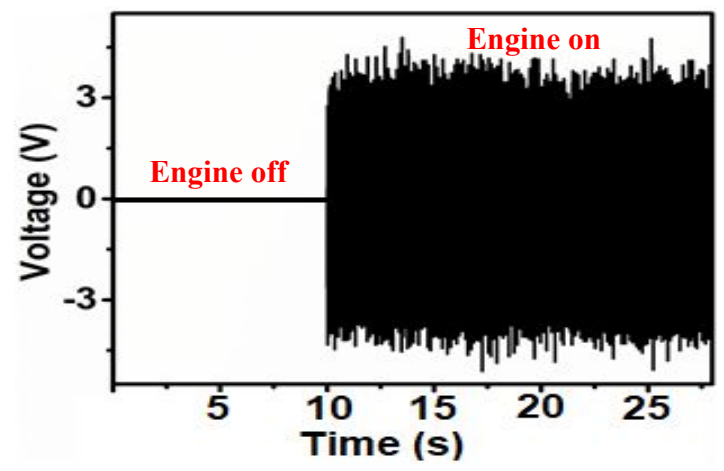

(c)

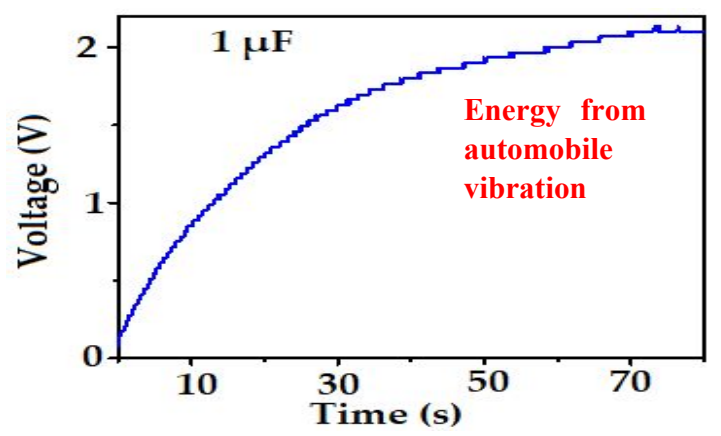

(b)
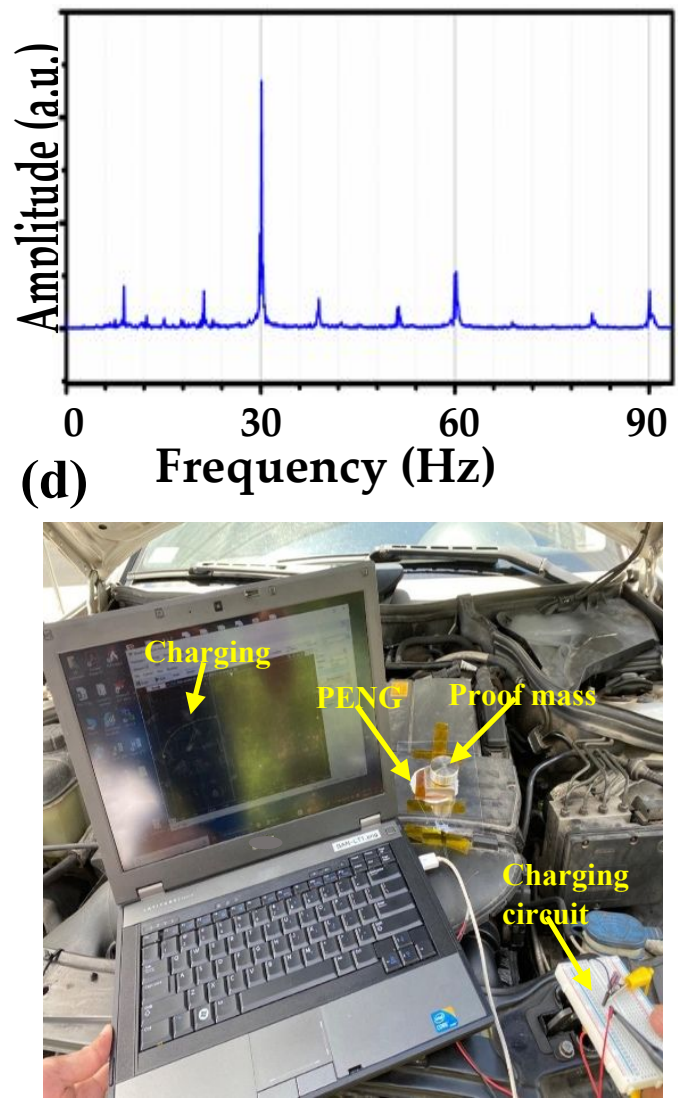

Figure S12. Application of the PENG for SHM (a) Output voltage from a PENG mounted on a automobile car engine for both on and run condition. (b) Corresponding frequency domain distribution via Fast Fourier Transform while the maximum peak occur at $29 \mathrm{~Hz}$ (c) Output charging voltage of a commercial capacitor $(1 \mu \mathrm{F})$ by a single PENG by an automobile engine (Mercedes-Benz car); (d) the corresponding digital photo of charging capacitor by engine vibration at stand still. 


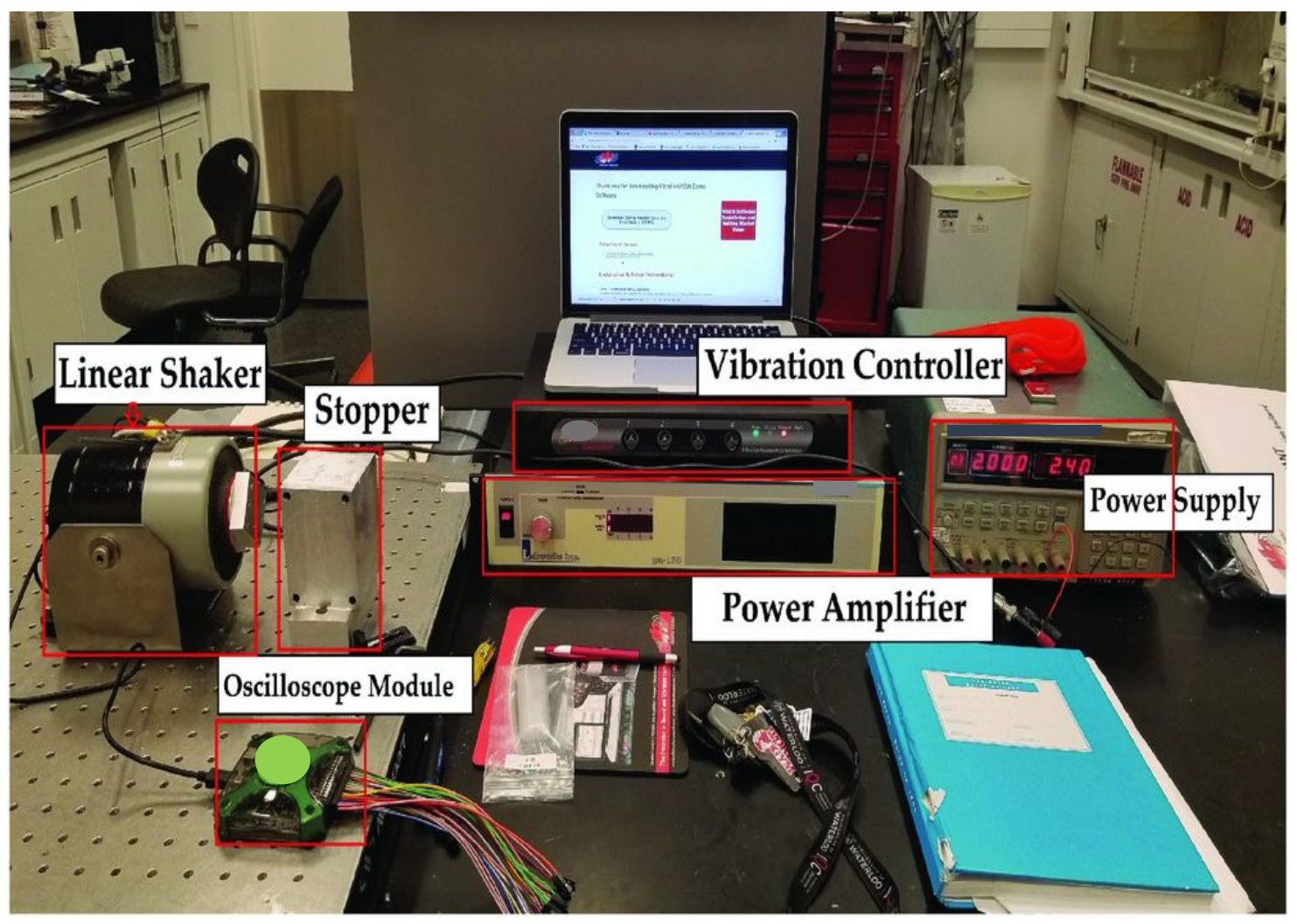

Figure S13. General setup of the piezoelectric characterization system. The system includes a closed- loop controller, a linear shaker, and a power amplifier unit to provide sinusoidal waves simulating a vibration source with known amplitude and frequency.[63]

Table S2: Performance comparison of various PVDF-based piezoelectric nanogenerators based on different chemical composition and experimental conditions such as the amount of force applied, operation mode, device area, and output load resistance.

\begin{tabular}{|c|c|c|c|c|c|c|}
\hline Materials & Fillers & Structures & $\begin{array}{c}\text { Open- } \\
\text { circuit } \\
\text { voltage }\end{array}$ & $\begin{array}{c}\text { Short- } \\
\text { circuit } \\
\text { current }\end{array}$ & Power & References \\
\hline $\mathrm{P}(\mathrm{VDF}-\mathrm{TrFE})$ & - & Flat film & $7 \mathrm{~V}$ & $58 \mathrm{nA}$ & - & {$[1]$} \\
\hline $\mathrm{P}(\mathrm{VDF}-\mathrm{TrFE})$ & - & $\begin{array}{c}\text { Curved } \\
\text { film }\end{array}$ & $120 \mathrm{~V}$ & $700 \mu \mathrm{A}$ & 3.9 & {$[2]$} \\
\hline $\mathrm{PVDF}$ & 3D Nanofillers & Flat film & $\begin{array}{c}11 \mathrm{~V} @ \\
729 \mu \varepsilon \\
\text { (strain) }\end{array}$ & - & $72 \mu \mathrm{cm} / \mathrm{cm}^{3}$ & {$[3]$} \\
\hline PVDF/Ba $\left(\mathrm{Ti}_{0.9} \mathrm{Zr}_{0.1}\right) \mathrm{O}_{3}$ & Nanocubes & Flat film & $\begin{array}{c}11.99 \mathrm{~V} \\
@ 11 \mathrm{~N}\end{array}$ & $\begin{array}{c}1.36 \mu \mathrm{A} @ \\
11 \mathrm{~N}\end{array}$ & - & {$[4]$} \\
\hline
\end{tabular}




\begin{tabular}{|c|c|c|c|c|c|c|}
\hline $\mathrm{PVDF} / \mathrm{ZnO}$ & Nanoparticles & Flat film & $\begin{array}{c}24.5 \mathrm{~V} @ \\
28 \mathrm{~N}\end{array}$ & $\begin{array}{c}1.7 \mu \mathrm{A} @ 28 \mathrm{~N} \\
28\end{array}$ & - & {$[5]$} \\
\hline $\mathrm{PVDF} / \mathrm{SnO}_{2}$ & Nanosheets & Flat film & $42 \mathrm{~V}$ & $\begin{array}{c}6.25 \\
\mu \mathrm{A} / \mathrm{cm}^{2}\end{array}$ & $4900 \mathrm{~W} / \mathrm{m}^{3}$ & [6] \\
\hline PVDF/AlO-rGO & Nanoparticles & Flat film & $\begin{array}{c}36 \mathrm{~V} @ \\
31.19 \mathrm{kPa}\end{array}$ & $\begin{array}{l}0.8 \mu \mathrm{A} @ \\
31.19 \mathrm{kPa}\end{array}$ & $27.97 \mu \mathrm{W}$ & [7] \\
\hline PVDF/ZnO & Nanowires & Flat film & $6.9 \mathrm{~V}$ & $0.96 \mu \mathrm{A}$ & $6.624 \mu \mathrm{W}$ & [8] \\
\hline $\mathrm{PVDF} / \mathrm{BaTiO}_{3}$ & Nanowires & Flat film & $14 \mathrm{~V}$ & $4 \mu \mathrm{A}$ & $1.5 \mu \mathrm{W}$ & [9] \\
\hline $\mathrm{PVDF} / \mathrm{BaTiO}_{3}$ & Nanoparticles & Flat film & $\begin{array}{c}10 \mathrm{Vp}-\mathrm{p} @ \\
2 \mathrm{~N}\end{array}$ & $\begin{array}{c}2.5 \mu \mathrm{Ap}-\mathrm{p} \\
@ 2 \mathrm{~N}\end{array}$ & $5.8 \mu \mathrm{W}$ & [10] \\
\hline PVDF & - & $\begin{array}{l}\text { Electrospun } \\
\text { membrane }\end{array}$ & $\begin{array}{l}48 \mathrm{~V} @ \\
8.3 \mathrm{kPa}\end{array}$ & $\begin{array}{c}6 \mu \mathrm{A} @ 8.3 \\
\mathrm{kPa}\end{array}$ & $51 \mu \mathrm{W}$ & [11] \\
\hline PVDF & - & Fabric & $\begin{array}{l}14 \mathrm{~V} @ \\
0.1 \mathrm{MPa}\end{array}$ & $\begin{array}{c}29.8 \mu \mathrm{A} @ \\
0.1 \mathrm{MPa}\end{array}$ & $5.1 \mu \mathrm{W} / \mathrm{m}^{2}$ & [12] \\
\hline PVDF/NiO@ $\mathrm{SiO}_{2}$ & Nanoparticles & Flat film & $\begin{array}{l}53 \mathrm{~V} @ \\
0.3 \mathrm{MPa}\end{array}$ & $\begin{array}{c}0.3 \mu \mathrm{A} \cdot \mathrm{cm}- \\
2 @ 0.3 \\
\mathrm{MPa}\end{array}$ & $685 \mathrm{~W} / \mathrm{m}^{3}$ & [13] \\
\hline PVDF/NKNS-LT-BZ & Nanoparticles & Flat film & $\begin{array}{c}18 \mathrm{~V} @ \\
50 \mathrm{~N}\end{array}$ & $\begin{array}{c}2.6 \mu \mathrm{A} @ \\
50 \mathrm{~N}\end{array}$ & - & [14] \\
\hline $\mathrm{PVDF} / \mathrm{ZnO}$ & Nanorods & $\begin{array}{c}\text { Electrospun } \\
\text { membrane }\end{array}$ & $85 \mathrm{~V}$ & $2.2 \mu \mathrm{A}$ & - & [15] \\
\hline PVDF/ZnO & Nanoparticles & $\begin{array}{l}\text { Flat film } \\
\text { (Porous) }\end{array}$ & $\begin{array}{c}84.5 \mathrm{~V} @ \\
2 \mathrm{KPa}\end{array}$ & $\begin{array}{c}22 \mu \mathrm{A} @ \\
2 \mathrm{KPa}\end{array}$ & $0.46 \mathrm{~mW}$ & This work \\
\hline
\end{tabular}

\section{References}

(1) Pi, Z.; Zhang, J.; Wen, C.; Zhang, Z-B.; Wu, D. Flexible Piezoelectric Nanogenerator Made of Poly (vinylidenefluoride-cotrifluoroethylene) (PVDF-TrFE) Thin Film, Nano Energy 2014, 7, 33-41.

(2) W. S. Jung, W. S.; Lee, M. J.; Kang, M. K; Moon, H. G.; Yoon, S. J.; Baek, S. H. Powerful Curved Piezoelectric Generator for Wearable Applications, Nano Energy 2015, 13, 174-181.

(3) Yang, L.; Zhao, Q.; Chen, K.; Ma, Y.; Wu, Y.; Ji, H.; and Qiu, J. PVDF-Based Composition-Gradient Multilayered Nanocomposites for Flexible High-Performance Piezoelectric Nanogenerators, ACS Appl. Mater. Interfaces 2020, 12, 11045-11054.

(4) Alluri, N. R.;Saravanakumar, B.; Kim, S. J. Flexible, Hybrid Piezoelectric Film (BaTi(1$\mathrm{x}) \mathrm{Zr}(\mathrm{x}) \mathrm{O} 3$ )/PVDF Nanogenerator 18 Nanogenerator as a Self-Powered Fluid Velocity Sensor, ACS Appl. Mater. Interfaces 2015, 7, 9831-9840.

(5) Thakur, P.; Kool, A.; Hoque, N. A.; Bagchi, B.; Khatun, F.; Biswas, P. Superior Performances of In Situ Synthesized ZnO/PVDF Thin Film Based Self-Poled Piezoelectric Nanogenerator and Self-Charged Photo-Power Bank with High Durability, Nano Energy 2018, 44, 456-467. 
(6) Kar, E.; Bose, N.; Dutta, B.; Banerjee, S.; Mukherjee, N.; Mukherjee, S. 2D $\mathrm{SnO}_{2} \mathrm{Nanosheet} / \mathrm{PVDF}$ Composite Based Flexible, Self-cleaning Piezoelectric Energy Harvester. Energy Conversion and Management 2019, 184, 600-608.

(7) Karan, S. K.; Bera, R.; Paria, S.; Das, A. K.; Maiti, S.; Maitra, A. An Approach to Design Highly Durable Piezoelectric Nanogenerator Based on self-Poled PVDF/AlO-rGO Flexible Nanocomposite with High Power Density and Energy Conversion Efficiency, Adv. Energy Mater. 2016, 6, 1601016.

(8) Saravanakumar, B.; Soyoon, S.; Kim, S. J. Self-Powered pH Sensor Based on a Flexible OrganicInorganic Hybrid Composite Nanogenerator, ACS Appl. Mater. Interfaces 2014, 6, 13716-13723.

(9) Jeong, C. K.; Baek, C.; Kingon, A. I.; Park, K. I.; Kim, S. H. Lead-free Perovskite Nanowire-Employed Piezopolymer for Highly Efficient Flexible Nanocomposite Energy Harvester, Small 2018, 14, 1704022.

(10) Yaqoob, U.; Uddin, A. S. M. I.; Chung, G. S. A Novel Tri-layer Flexible Piezoelectric Nanogenerator Based on Surface-Modified Graphene and PVDF-BaTiO3 Nanocomposites, Applied Surface Science 2017, 405,420426 .

(11) Maity, K.; Mandal, D. All-Organic High-Performance Piezoelectric Nanogenerator with Multilayer Assembled Electrospun Nanofiber Mats for Self-Powered Multifunctional Sensors. ACS Appl. Mater. Interfaces 2018, 10, 18257-18269.

(12) Soin, N.; Shah, T. H.; Anan, S. C.; Geng, J.; Pornwannachai, W.; Mandal, P. Novel "3-D spacer” All Fibre Piezoelectric Textiles for Energy Harvesting Applications, Energy Environ. Sci. 2014, 7, 1670-1679.

(13) Dutta, B.; Kar, E.; Bose, N.; Mukherjee, S. NiO@SiO2/PVDF: A Flexible Polymer Nanocomposite for a High Performance Human Body Motion-Based Energy Harvester and Tactile E-Skin Mechanosensor, ACS Sustainable Chemistry \& Engineering 2018, 6, 10505-10516.

(14) Zhang, C.; Fan, Y.; Li, H.; Li, Y.; Zhang, L.; Cao, S. Fully Rollable Lead-free Poly(vinylidene fluoride)-Niobate Based Nanogenerator with Ultra-Flexible Nano-Network Electrodes, ACS Nano 2018, $12,4803-4811$.

(15) Li, J.; Chen, S.; Liu, W.; Fu, R.; Tu, S.; Zhao, Y. High Performance Piezoelectric Nanogenerators Based on Electrospun ZnO Nanorods/ Poly(vinylidene fluoride) Composite Membranes. J. Phys. Chem. C 2019, 123, 11378-11387. 